EESTI NSV TEADUSTE AKADEEMIA TOIMETISED 1955. IV kd., nr. 1 ИЗВЕСТИЯ АКАДЕМИИ НАУК ЭСТОНСКОИ ССР 1955. ТоМ IV, № 1

\title{
К ВОПРОСУ О ХИМИЧЕСКОМ СОСТАВЕ И БАКТЕРИЦИДНЫХ СВОЙТВАХ ЭСТОНСКИХ ЛЕЧЕБНЫХ ГРЯЗЕЙ
}

\author{
Н. А. ДЕРБЕНЦЕВА, \\ кандидат химнческих наук \\ А. М. ХОВАНОВА, \\ кандндат меднцннских наук
}

Минеральный состав лечебных грязей Әстонской ССР, физико-химические их свойства и бальнеологическое действие изучались эстонскими химиками, бальнеологами и врачами. Все проведенные в этом направлении работы обобщены в монографии В. Вади, изданной в 1947 году $\left({ }^{3}\right)$.

Грязевые месторождения Эстонии в период 1947-1948 годов исследовались экспедицией Центрӑльного института курортологии. В результате этой работы получена сравнительная оценка грязевых месторождений, проведено изучение запасов грязи и организации грязевого хозяйства. Одновременно дана микробиологическая, химическая и физикохимическая характеристика лечебных грязей двух основных месторождений Эстонии - Хаапсалу и Кингисеппа (Курессааре) *. C 1950 года работа по изучению лечебных грязей в Эстонской ССР была прекращена и возобновилась только в начале 1953 года. Предшествующими исследованиями было установлено, что эстонские лечебные грязи, наряду с хорошей водоудерживающей способностью, значительным содержанием органического вещества и высокой теплоемкостью, обладают весьма значительной адсорбционной способностью и большой величиной сопротивления сдвигу, что при наличии небольшой засоренности позволяет считать нх, особенно грязь Хаапсалуского залива, весьма ценными в лечебном отношении.

Проведенными в течение последнего десятилетия экспериментальными исследованиями доказано, что лечебное значение грязей основывается не только на их физико-химических и тепловых свойствах, но и на наличии в них органических веществ, обладающих химическим и биологическим действием на организм. В связи с этим большое значение приобретает углубленное изучение органического вещества грязей, являющегося основным субстратом для жизнедеятельности грязевой микрофлоры и обусловливающего происходящие в них биохимические процессы.

Интерес к органическим компонентам лечебных грязей особенно возрастает в связи с установлением их бактерицидных свойств.

* Работы, проведенные Центральным институтом курортологии, оформлены в виде рукописных отчетов. 
Благодаря работам, выполненным силами Государственного бальнеологического института на Кавказских минеральных водах, установлено, что лечебная грязь Тамбуканского озера обладает способностью in vitro и in vivo задерживать рост ряда патогенных микробов (стрептококка, стафилококка, кишечной и синегнойной палочки и др.) и даже убивает их, т. е. оказывает бактериостатическое и бактерицидное действие $\left({ }^{4,5,6}\right)$.

Эти работы получили практическое применение при лечении грязью военнотравматических повреждений, кожных заболеваний и открытых инфицированных ран.

В дальнейшем из Тамбуканской грязи А. Л. Шинкаренко $\left({ }^{14,15}\right)$ выделил смеси органических веществ, обладающих сильным бактерицидным действием по отношению к ряду патогенных микробов. Шинкаренко удалось получить из смолообразных фракций этой грязи вещества, подобные пенициллину, грамицидину и тиротрицину. В результате проверки бактерицидного действия выделенных веществ, а также последующего выделения О. Ю. Волковой $\left({ }^{7}\right)$ из Тамбуканской грязи большого количества штаммов плесневых грибков из рода Penicillium, актиномицетов и ряда спороносных культур, продуцирующих близкое к грамицидину вещество, доказана тесная связь бактерицидных веществ грязи с населяющими ее микроорганизмами, продуктами жизнедеятельности которых они являются. Отсюда был сделан вывод, что условия, оптимальные для развития грязевой микрофлоры, являются оптимальными и для накопления антибиотических веществ.

Антибиотические свойства лечебных грязей служат ценным дополнением к другим, уже известным их физико-химическим свойствам и существенно расширяют сферу их лечебного применения.

Эстонские лечебные грязи, отличающиеся большим содержанием органического вещества и обильной микрофлорой, представляют собой весьма интересный объект с точки зрения исследования их биологической активности.

Настоящая работа, являясь первой попыткой подойти к изучению данного вопроса, ставит задачей восполнить в известной степени пробел в изучении местных лечебных грязей с целью расширения путей применения их в медицинской практике республики.

\section{Химическая характеристика органического вещества Хаапсалуской лечебной грязи}

Изучаемая нами грязь была получена из Хаапсалуского грязехранилища в январе 1953 года. В грязехранилище она поступила в сентябре 1952 года из Хаапсалуского залива, где была взята на расстоянии 1 км от берега. Грязью данного хранилища пользуются курорты Эстонской ССР в Хаапсалу и Пярну.

За время пребывания в зимний период в грязехранилище грязь подвергалась промерзанию, в связи с расположением грязехранилища на открытом месте во дворе. В лабораторию было доставлено 50 кг грязи, взятой из различных мест грязехранилища.

Перед производством анализов грязь была выдержана в лаборатории при комнатной температуре в течение $3-4$ месяцев. Средние пробы отбирались по общепринятым методам. Были исследованы основные показатели грязи и групповой химический состав органического вещества. Затем изучались бактерицидные свойства грязи в целом и отдельных, выделенных из нее групп веществ.

Содержание органического вещества определялось по методу мокрого сжигания Тюрина-Кноппа с применением весового учета образовавшегося 
$\mathrm{CO}_{2} \cdot\left({ }^{13}\right)$. Содержание сероводорода устанавливалось титрованием $0,01 \mathrm{~N}$ раствором иода по методу Кашинского $(10,11)$.

Количество битумов определялось экстрагированием подсушенной грязи спирто-бензолом (1:1) в аппарате Сокслета $\left({ }^{12}\right)$.

Общий азот определялся по методу Кьельдаля с применением катализаторов, ускоряющих процесс сжигания органического вещества $\left({ }^{16}\right)$.

Остальные показатели были установлены стандартным методом, выработанным для анализа лечебных грязей $\left({ }^{2}\right)$.

Для установления количественного состава основных групп органического вещества и для определения легкогидролизуемой фракции был проведен гидролиз нативной грязи, взятой из Хаапсалуского залива и грязехранилища, и той же грязи, подвергнутой предварительной обработке. Гидролиз проводился по методу Кизеля с учетом внесенных Л. Н. Александровой для гидролиза почв видоизменений, вызванных наличием растворимых в кислой среде минеральных соединений $\left({ }^{1}\right)$. Установление гидролизуемой части органического вещества основывалось на количественном учете редуцирующих сахаров по методу Бертрана $\left({ }^{9}\right)$.

Определялись: а) легкогидролизуемые вещества (гемицеллюлозы); б) трудногидролизуемые вещества (клетчатка и трудногидролизуемые пентозаны и гексозаны); в) негидролизуемый остаток (лигнино-гумусовый комплекс).

Далее, изучалась динамика-изменения химического состава грязи в зависимости от времени года, условий ее обработки и хранения. Определялось содержание органического вещества, сероводорода, общего азота, гидролизуемой фракции и общего количества грязевой микрофлоры в различных образцах грязи.

Результаты проведенных опытов представлены в таблицах. Результаты эти являются средними из 5-6 параллельных опытов.

Исследованные нами образцы Хаапсалуской лечебной грязи отличаются значительным содержанием органического вещества ( $7-8 \%$ от веса сухой исходной грязи), большой водопоглощающей способностью, слабой засоренностью и незначительным количеством сероводорода $(0,23$ мг на 1 г сырой грязи).

Таблица 1

Основные показатели грязи из Хаапсалуского грязехранилища *

\section{Наименование показателей}

Содержание воды (в \% от исходной грязи)

Неозоляемая часть

Потери от прокаливания (по разности)

Разлагаемые карбонаты

" хлориды

Засоренность

Сероводород

Общий азот

, углерод

Органическое вещество

Легкогидролизуемые вещества (гемицеллюлозы)

Трудногидролизуемые вещества (клетчатка)

Лигнино-гумусовый комплекс

Битумоподобные вещества
В процентах от веса абс. сухого вешества грязи

* Грязевой раствор, полученный фильтрацией грязи в количестве $35,5 \%$ от веса исходной грязи, содержит $0,58 \%$ сухих веществ, удельный вес его 1,005 и $\mathrm{pH}=7,3$. 
Содержание отдельных групп вещества по отношению к общему количеству органического вещества

Наименование компонентов

В процентах от общего количества органического вещества

Битумоподобные вещества

Легкогидролизуемые вещества (гемицеллюлозы)

Трудногидролизуемые вещества (клетчатка)

Лигнино-гумусовый комплекс

Общий азот

Азот лигнино-гумусового комплекса

22,41

16,42

2,16

59,01

8,50

4,25

Грязевой раствор имеет малый удельный вес, небольшую величину рН и содержит незначительное количество сухих веществ, что указывает на низкую степень его минерализации.

В составе органического вещества Хаапсалуской грязи значительное место занимают битумы $(22,4 \%)$. Количество легкогидролизуемых углеводов превышает количество трудногидролизуемых в 8-10 раз, что является весьма положительным фактором $(4,5)$, ибо легкогидролизуемые вещества, образующиеся в результате ферментативного гидролиза, легко усваиваются микроорганизмами и обеспечивают протекание микробиологических процессов, играющих большую роль в образовании грязи, ее регенераций и в проявлении ее биологической активности (табл. 3).

Взятая осенью непосредственно из залива грязь отличалась от грязи, подвергавшейся промерзанию в грязехранилище, бо́льшим содержанием органического вещества, легкогидролизуемой его части и общего количества микроорганизмов в 1 г сухой грязи (табл. 3). Это явление вполне закономерно, ибо грязь осенью, а на юге даже в начале зимы, обогащается остатками отмирающих растительных и животных организмов, служащих богатым материалом для грязевой микрофлоры и стимулирующих происходящие в грязи биохимические процессы.

Динамика изменения химического состава грязи в зависимости от условий ее обработки и хранения представляет интерес с точки зрения установления степени и длительности нагревания грязи при приготовлении грязевых аппликаций, выяснения влияния введения органических веществ и условий термостатирования в случаях регенерации грязи, а также возможности высушивания грязи при хранении или для производства отдельных анализов. Из проведенных опытов (табл. 3) следует, что высушивание грязи при $90^{\circ} \mathrm{C}$ и нагревание ее на водяной бане вызывает в последующем уменьшение содержания органических веществ, вероятно за счет удаления летучих органических соединений и кислот и усиления процессагидролиза и ассимиляции усвояемых органических соединений микроорганизмами. Количество легкогидролизуемых веществ при этом несколько увеличивается, а количество азота уменьшается, но очень незначительно. При нагревании происходит накопление газообразных продуктов, вызывающих вспучивание грязевой массы. Увеличение количества сероводорода в результате нагревания, очевидно, можно объяснить оживлением деятельности сульфатредуцирующих бактерий.

Количество микроорганизмов в 1 г грязи в результате высушивания и непосредственно после нагревания на водяной бане резко уменьшается за счет гибели нестойкой части грязевой микрофлоры. При дальнейшей длительной выдержке прогретой грязи в закрытом сосуде (до 1 месяца) количество микроорганизмов интенсивно возрастает. При термостатиро- 


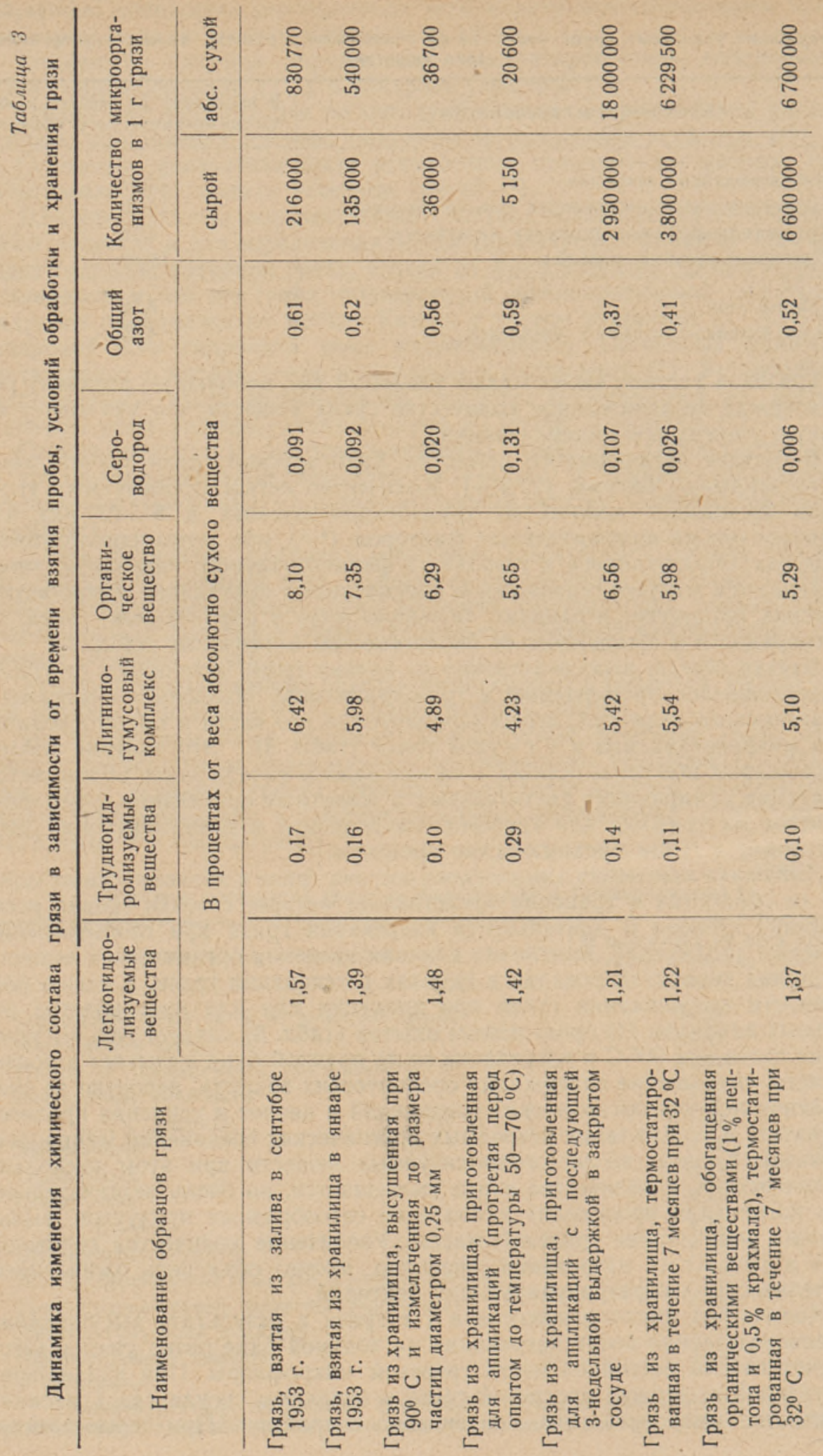


вании в течение 3-6 месяцев и, тем более, при сопутствующем термостатированию обогащении грязи органическими веществами, количество микроорганизмов в наших опытах тоже увеличилось, но не в такой степени, вероятно вследствие происходившего при этом подсыхания грязи. Во всех случаях длительной термичёской обработки грязи увеличение микрофлоры сопровождалось уменьшением общего содержания органических веществ на $1-2 \%$, уменьшением общего азота и легкогидролизуемой фракции.

Общая картина изменения химического состава грязи при прогревании еще раз говорит в пользу применения его при грязелечении. Нагревание грязи до температуры $50-60^{\circ} \mathrm{C}$ при приготовлении аппликаций, помимо ценного термического действия на организм, вызывает увеличение образования легкоусвояемых органических веществ и выделения летучих ее компонентов. При этом, как подтверждает и медицинская практика, комплексом этих летучих веществ усиливается раздражение нервных рецепторов кожи $\left({ }^{8}\right)$.

Нужно думать, что нагревание и термостатирование грязи должны способствовать повышению ее биологической активности.

\section{Исследование бактерицидных свойств Хаапсалуской лечебной грязи}

Исследования биологической активности Хаапсалуской лечебной грязи проводились нами с целью установления ее бактерицидных свойств по отношению к следующим патогенным и условно-патогенным микробам: белый стафилококк, гемолитический стрептококк и протей, выделенные из гноя раны, палевый и золотистый стафилококки, выделенные из зева ребенка, больного ревматизмом, кишечная палочка, выделенная из испражнений ребенка-ревматика.

Для определения бактерицидности грязи применялся чашечный метод, заключавшийся в нанесении грязевых комочков-аппликаций на поверхность агара в чашках, засеянных предварительно испытуемыми тест-микробами.

Доказательством бактерицидного действия явились зоны с отсутствием роста микробов (стерильные зоны), образовавшиеся вокруг грязевых комочков после инкубации в термостате при $37^{\circ} \mathrm{C}$ в течение 24 часов. Таким методюм было проведено около 200 испытаний, результаты которых показали, что грязь из Хаапсалуского грязехранилища, подвергавшаяся в свое время промерзанию, при применении данного метода почти совсем не проявила бактерицидных свойств. Комочки этой грязи, будучи нанесены на чашки с газоном указанных микробов, дают лишь с белым стафилококком и кишечной палочкой незначительные и слабовыраженные

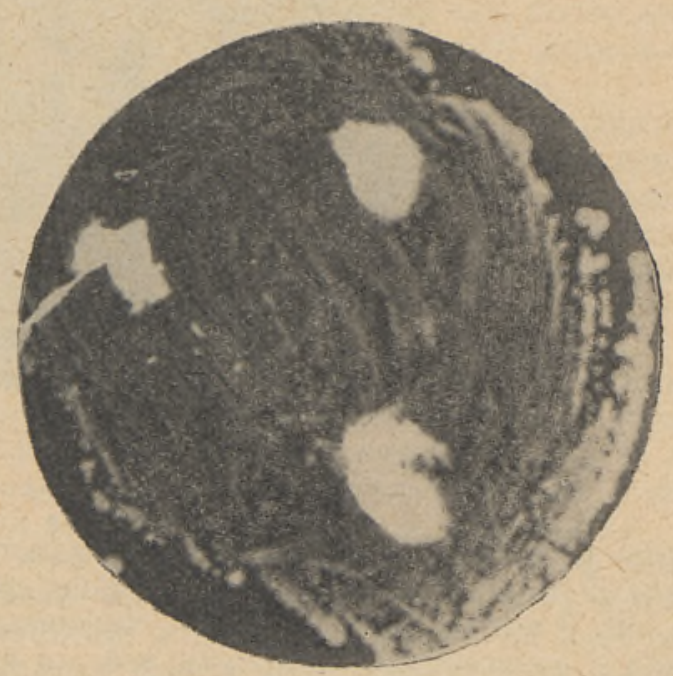

Рнс. 1. 
зоны просветления шириной 1 мм. В чашках, засеянных другими микроорганизмами, зоны просветления не были обнаружены вовсе.

Бактерицидная способность Хаапсалуской грязи, взятой в сентябре 1953 года непосредственно из залива, несколько бо́льшая и проявилась в бо́льшем количестве опытов. Так, на рис. 1 показан результат опытов, в

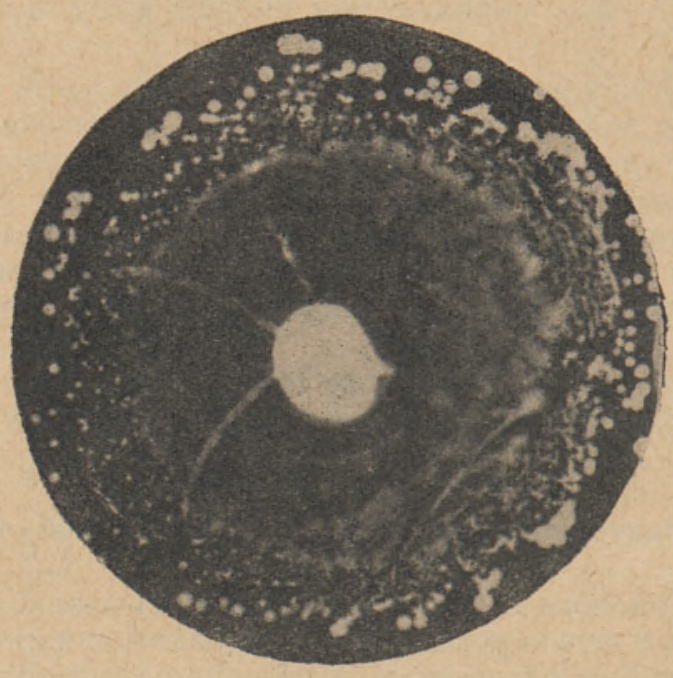

Рнс. 2.

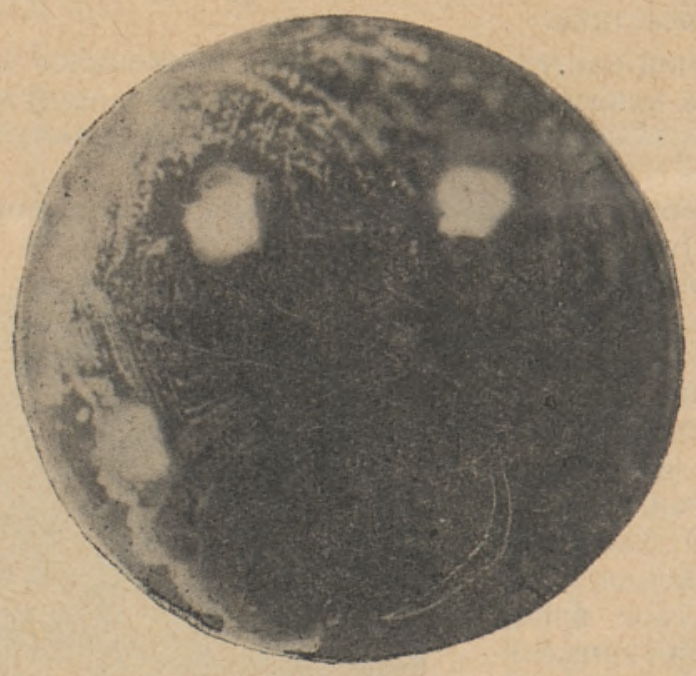

Рис. 3.

которых в чашке с агаром, засеянном золотистым стафилококком, комочки грязи из Хаапсалуского грязехранилища совсем не дали зон нросветления. На рис. 2 показано, что в чашке, засеянной культурой палевого стафилококка с нанесенными комочком той же грязи, взятой из Хаапсалуского залива, образовалась нечетко выраженная стерильная зона шириной 5$6 \mathrm{MM}$. 
С целью активации бактерицидных свойств грязи, взятой из грязехранилища, мы провели ряд опытов по обогащению ее органическими веществами с одновременной инкубацией в термостате в течение двух недель при $30-32^{\circ} \mathrm{C}$.

В состав органических веществ, введенных нами в грязь в различных комбинациях в количестве от 0,1 до $1 \%$ от веса исходной грязи, входили пептон, глюкоза, крахмал, свежая измельченная трава и др. Обогащенная таким образом грязь выдерживалась предварительно в термостате, и небольшие комочки ее накладывались на чашки с агаром, засеянные культурами стафилококка, стрептококка, протея и кишечной палочки. После 24-часовой инкубации в термостате стерильные зоны наблюдались почти в каждом посеве, особенно на чашках, засеянных золотистым стафилококком и кишечной палочкой, и достигали в некоторых случаях ширины

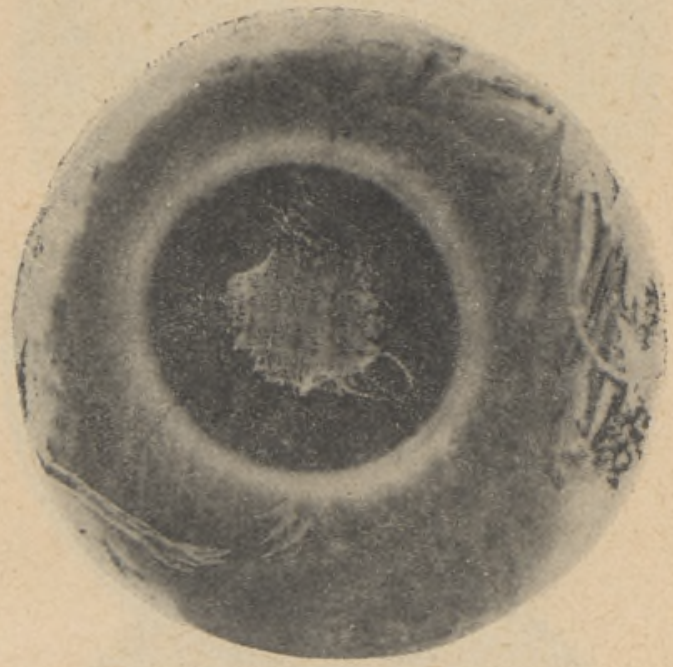

Pric. 4.

8-10 мм. При этом нередко приходилось наблюдать, что при более длительном выдерживании посевов в термостате (свыше 48 часов) в стерильных зонах возникал вторичный рост грязевых микроорганизмов.

На рис. 3 изображены зоны просветления, образовавшиеся в культуре золотистого стафилококка в результате воздействия на нее образца грязи Хаапсалуского грязехранилища, который был предварительно обогащен введением $1 \%$ пептона и $0,1 \%$ лимоннокислого натрия с последующей 2 -недельной выдержкой в термостате при $32^{\circ} \mathrm{C}$. После 24 -часовой инкубации в чашках с комочками грязи, засеянных культурой золотистого стафилококка, образовались стерильные зоны шириной 5-8 мм.

Результаты этих опытов дают основание считать, что Хаапсалуская грязь, отличающаяся по происхождению, составу и климатическим условиям формирования от южных грязей материкфвых озер, в частности от грязи Тамбуканского озера, обладает бактерицидными свойствами, слабо выраженными в нативной грязи и возрастающими при ее обогащении.

С целью изучения основных носителей бактерицидных свойств нами были проведены опыты по выделению из грязи комплекса веществ, извлекаемых органическими растворителями, и по исследованию их бактерицидного действия. Для этого исходная, слегка подсушенная грязь многократно экстрагировалась смесью подкисленного спирта и ацетона на хо- 
лоду до исчезновения окрашиваемости растворителя. После отгонки смеси растворителей и сушки остатка в вакуум-эксикаторе было получено зеленовато-коричневое смолообразное вещество (спирто-ацетоновый экстракт) с запахом сухих фруктов.

Вещество, извлеченное спирто-ацетоном, экстрагировалось затем хлороформом. Хлороформная фракция после отгонки растворителя и сушки в вакуум-эксикаторе представляет собой густую темнокоричневую массу с тем же, но более интенсивным запахом.

Не извлеченная хлороформом часть экстрагировалась смесью спиртобензина; таким образом был получен спирто-бензиновый экстракт, представляющий собою густую массу светлокоричневого цвета. Остаток, нерастворимый в хлороформе и спирто-бензине, составил IV фракцию.

В результате были получены четыре фракции:

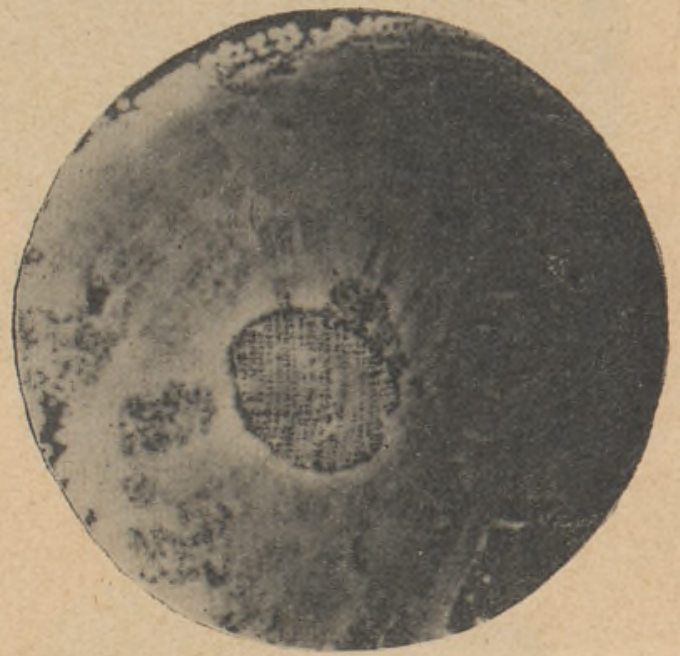

Рис. 4 a.

а) спирто-ацетоновая, б) хлороформная, в) спирто-бензиновая, г) остаток, нерастворимый в хлороформе и бензине. Было поставлено 70 опытов по определению бактерицидных свойств полученных экстрактов и установлено, что во всех случаях они обладают сильным бактерицидным действием по отношению ко всем вышеуказанным тест-микробам.

Опыты проводились по той же методике, только вместо комочков грязи на чашки, засеянные культурами тест-микробов, накладывались кусочки марли, пропитанные данным экстрактом. После 24-часовой инкубации в термостате при $37^{\circ} \mathrm{C}$ вокруг кусочка марли наблюдались совершенно стерильные, резко очерченные зоны шириной 10-15 мм и более.

Для исключения влияния бактерицидности самих растворителей, применяемых при экстрагировании грязи, следы которых могли сохраниться в экстрактах, параллельно мы накладывали на нашки, засеянные теми же культурами тест-микробов, кусочки марли, смоченные лишь этими растворителями. После соответствующей инкубации стерильные зоны или не были обнаружены вовсе, или если в отдельных случаях обнаруживались, то ширина их была в 10 раз меньше, чем в опытах с соответствующими экстрактами.

На рис. 4 изображены результаты бактерицидного действия спиртоацетоновой вытяжки грязи на культуру золотистого стафилококка; 
вокруг кусочка марли образовалась стерильная зона шириной 12 мм. $\mathrm{Ha}$ рис. $4 a$ показано бактерицидное действие бинарного растворителя спирто-ацетона на ту же культуру, в тех же условиях; при этом образовалась едва заметная стерильная зона шириной около 1 мм. На рис. 5 изображена стерильная зона шириной $10-12$ мм, образовавшаяся

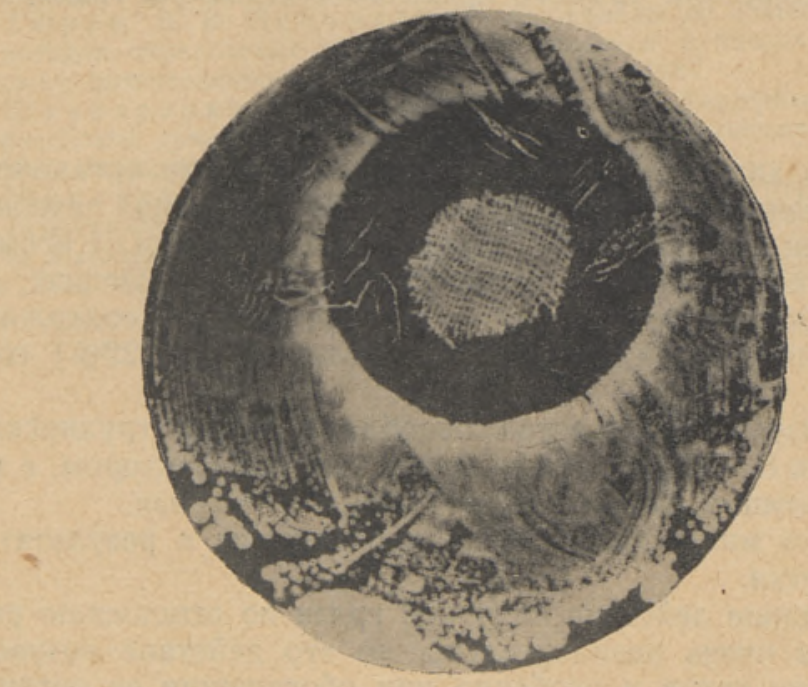

Рис. 5.

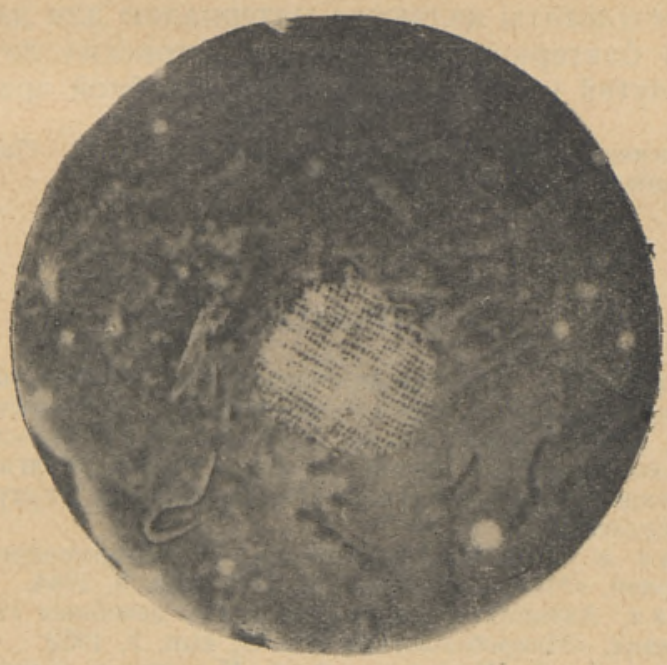

Рис. 5a.

в результате воздействия спирто-бензинового экстракта грязи на культуру кишечной палочки. Рис. $5 a$ показывает, что бинарный растворитель спирто-бензин, нанесенный на чашку с той же культурой, не образует стерильной зоны вовсе.

Комплекс веществ, извлекаемых органическими растворителями, повидимому, представляет собой в основном продукты жизнедеятельности 
грязевой микрофлоры и продукты химических превращений органического вещества грязи. Несомненно, он тесно связан с общим минеральным составом грязи и ее коллоидно-химической структурой.

Являясь, очевидно, основным началом биологической активности грязи, комплекс этих веществ, согласно нашим предварительным данным, по силе бактерицидного действия намного превышает исходную грязь.

\section{Выводы}

При изучении химического состава основных групп органического вещества и общих физико-химических свойств Хаапсалуской лечебной грязи, а также динамики изменения этих свойств в зависимости от времени года, условий обработки и хранения грязи установлено следующее:

1. Хаапсалуская грязь имеет относительно большое содержание органического вещества, значительную часть которого (до 22\%) составляют битумы.

Легкогидролизуемые вещества преобладают над трудногидролизуемыми примерно в 8-10 раз, что является важным фактором, в известной степени определяющим биохимическую активность грязи.

2. Нарастание микрофлоры грязи наблюдается в результате ее термической обработки.

3. Бактерицидное действие нативной грязи по отношению ряда патогенных микробов очень незначительно, но это действие возрастает при термостатировании грязи и особенно при обогащении ее органическими веществами. Компоненты же грязи, извлекаемые органическими растворителями, обладают сильно выраженным бактерицидным действием по отношению к тем же тест-микробам.

Полученные результаты являются материалом для дальнейших исследований природы бактерицидных свойств эстонских лечебных грязей и для нахождения путей их использования в лечебной практике.

Ннститут экспериментальной и клинической медицины Академии наук Эстонской ССР

Поступила в редакцию 19 IV 1954

\section{ЛИТЕРАТУРА}

1. Л. Н. Але кс анд ров в, К методике определения редуцирующих сахаров в почве, Ученые записки ЛГУ. Серия геолого-почвенно-географическая, вып. 1, 1935.

2. А. Н. Буне ев, В. А. К р и вошн я, В. И. Бахм ан, Простейшие методы анализа и ориентировочной оценки лечебных грязей, Медгиз, 1943.

3. В. В а ди, Эстонская лечебная грязь, Ученые записки Тартуского государственного университета, № 7, 1947.

4. О. Ю. Волков а и А. В. Бал а банов а, О бактерицидных свойствах Тамбуканской грязи, «Микробиология», т. XIII, вып, 6, 1944.

5. О. Ю. Волкова, Антибактериальные свойства лечебных грязей и условия их формирования, жМикробиология» т. XXI, вып, 2, 1952.

6. О. Ю. Волкова, А. Л. Ш инка ре нко, К вопросу о механизме бактерицидного действия Тамбуканской грязи, Труды Государственного бальнеологического института на Кавказских минеральных водах, тт. XXIII-XXV, 1946.

7. О. Ю. Волкова, А. Д. Т ашинская, Л. И. Лисевицкая, К вопросу об антибактериальном действии Тамбуканской грязи в опыте применения нового метода грязелечения инфищированных ран, Труды Государственного бальнеологического института на Қавказских минеральных водах; т. XXVIII, 1949.

8. 'Ф. Д. Д роби з, В. А. Щ ерб атская и Р. С. Мендельсон, Влияние Молтаевской грязи и продуктов ее отгона на некоторые показатели азотистого обмена в коже, Сборник «Лечебные свойства сапропелей озера Молтаево», Свердловск, 1951.

9. Н. И. Ив а н в, Методы физиологин и биохимни растений, Л., 1946. 
10. П. А. К ашин ски й, Определение общего содержания сероводорода в грязи, «Гидрохимические материалы», т. I, вып, 1-2, 1915.

11. П. А. К а ши н ски й, Об унификации методики анализа илов (лечебной грязи), Материалы совещания по методике анализа илов (лечебной грязи), М.-Л., 1949.

12. Т. А. С пе р ан ская, К вопросу о химическом составе органического вещества лечебных грязей, «Гидрохимические материалы», т. XVII, 1950.

13. И. В. Тюрин, В. В. Поном а ев а, Материалы по сравнительному изучению методов определения органического углерода в почвах, «Проблемы советского почвоведения», Сб. 2 и 3,$1936 ;$ сб. $4,1937$.

14. А. Л. Ш и н к а ре н ко, Химическая характеристика бактерицидных веществ Тамбуканской грязи, Труды Государственного бальнеологического института на Кавказских минеральных водах, т. XXVIII, 1949.

15. А. Л. Шин к а ре н ко, К вопросу о химической природе бактерицидных веществ Тамбуканской грязи, Труды Государственного бальнеологического института на Кавказских минеральных водах, тт. XXVI-XXVII, 1947.

16. O. Hallik, Mullateaduse ja agrokeemia praktikum, Tartu, 1948. 